\title{
Las relaciones económicas internacionales en la década del 80
}

\section{LA CONTINUIDAD DEL DEV ENIR INTERNACIONAL}

\section{LA DECADA DEL 70}

La década del 70 se inicia con un replanteamiento del rol de Estados Unidos en el sistema internacional que trae como consecuencia trascendentales cambios en la economía mundial. El apoyo brindado por los Estados Unidos a Europa y al Japón para la reconstrucción de sus economías durante las dos décadas anteriores ayudó a fortalecerlas, aumentando entre otras cosas la competividad de sus productos en el comercio internacional y motivando que a finales de la década del 60 la participación de Estados Unidos en la riqueza mundial decreciera de un $50 \%$ (1958) a un $33 \%$ (1968). La carga económica de la Guerra de Vietman, traducida en déficits de la balanza de pagos y el malestar creado entre los productores nacionales y los sindicatos por la competencia de los productos extranjeros originaron la formulación de la doctrina Nixor, la cual entraña esencialmente el abandono de la orientación ideológica de la política exterior americana, con una reducción de los compromisos económicos externos y un acercamiento a la Unión Soviética en busca de una distensión estratégica, el cual incluye la cooperación económica.

El logro del equilibrio estratégico y de un nuevo entendimiento entre las superpotencias, allana a los Estados Unidos el camino para intentar reajustar el sistema económico internacional y mejorar relativamente su posición en él, que se había visto deteriorada por el crecimiento de Europa y Japón. Estos tres actores comienzan en 1971 un severo enfrentamiento económico que, sin comprometer su solidaridad dentro de la alianza occidental, echa por tierra las reglas de juego del sistema económico internacional. Una cadena de acciones sorpresivas y unilaterales de estos gobiernos va jalonando la primera mitad de la década del 70 , en medio de sucesivas crisis que arrancan con el colapso del sistema monetario en 1971, siguen con el alza de precios de los alimentos y los productos básicos y alcanzan su clímax con el surgimiento de una recesión mundial desde 1973 y el alza de los precios del petróleo desde fines del mismo año. Estas crisis son indudablemente producto de 


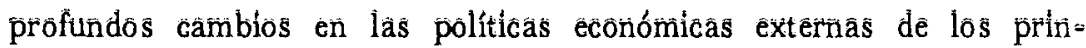

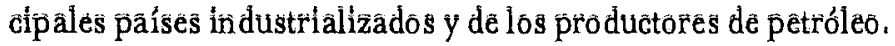

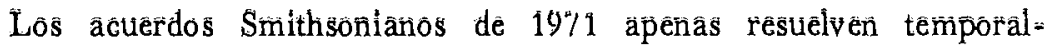

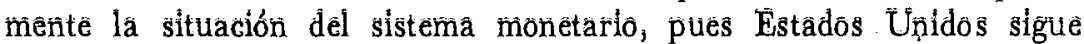

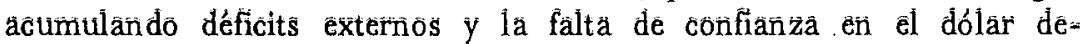

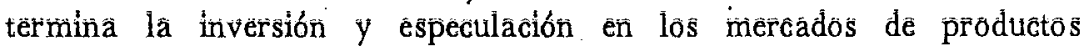

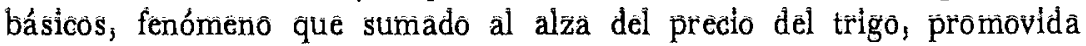

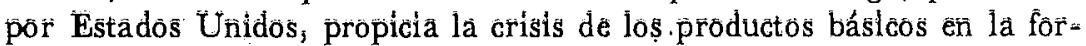

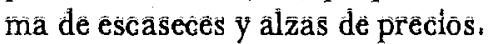

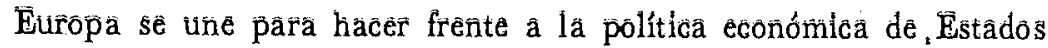

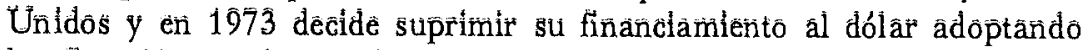

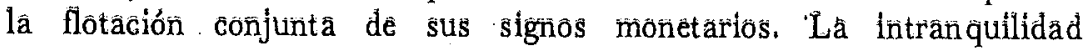

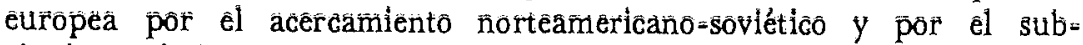

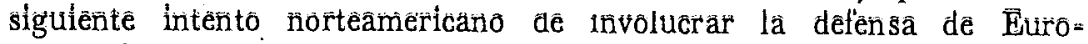

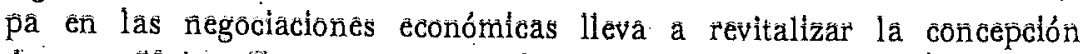

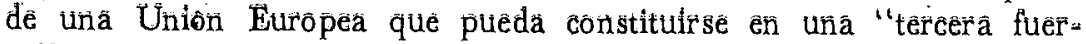

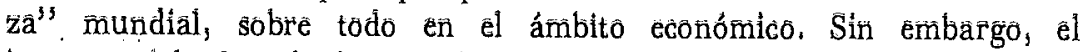

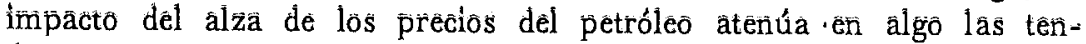

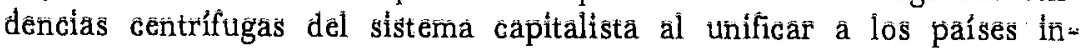

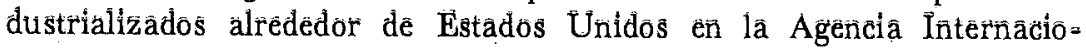

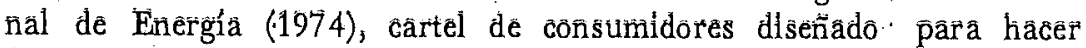

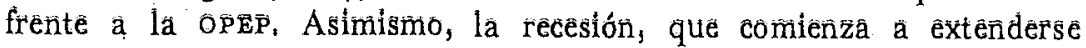

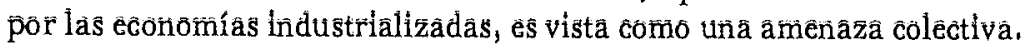

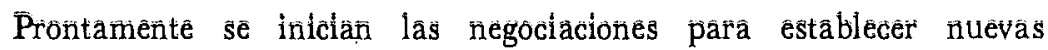

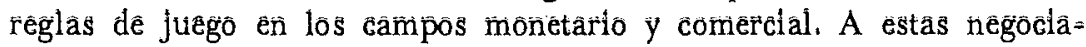

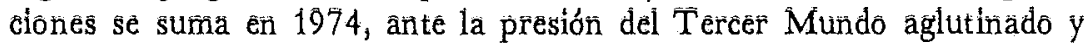

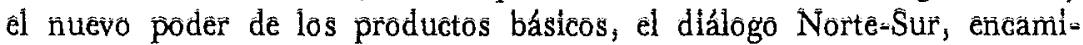

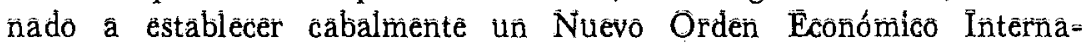

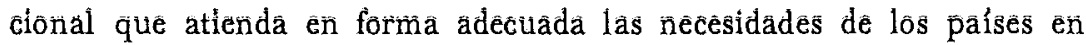

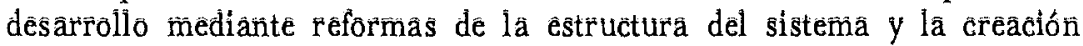

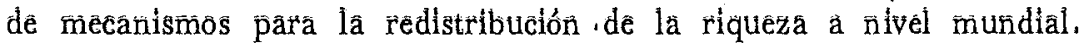

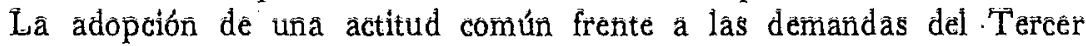

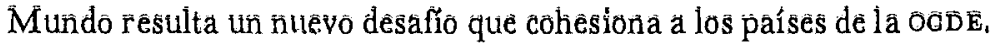

El espíritu de cuerpo de lōs países industrializados se refleja ên la realizaciónin anual de reuniones cumbres de los Jêfes de Esstado a partír de 1975, ên las cuâlés se intenta armonizär de manera general las líneas de crecimientoo de làs prificipales economías, côn mirâs á superấr los problemàs êconómícós globāles. Esto nó obsta pará que algunôs de ellos, como los de las Comunidades Europeas, emprendan y désarrollen arreglos con otros grupos de países para resolver de manera particular sus problemâs. Tál es el câsô del diálógo Eưrò-Arábe y de lās cônvênció- 
nes de Lomé con el Grupo Africa-Caribe-Pacífico (ACP) constituido por 57 países en desarrollo.

La simultánea cohesión y flexibilidad de los países industrializados como grupo se pone de relieve a raíz de la invasión soviética a Afganistán (1979), cuando sus reacciones individuales, al mismo tiempo que confirman el debilitamiento del liderazgo norteamericano, revelan que la concepción norteamericana de la détente y de la cooperación capitalista-comunista es distinta y reposa sobre bases diferentes que las de Europa y Japón.

En tanto que aún no se logra acordar un nuevo marco para el sistema monetario internacional, las negociaciones comerciales multilaterales culminan en 1979, estableciendo un marco llamado a asegurar la liberalización del comercio frente a la amenaza del mercantilismo, sin prestar especial atención a las necesidades de los países en desarrollo.

En la perspectiva de la estrategia internacional de desarrollo es muy poco lo que se avanza, debido principalmente a las desfavorables consecuencias que tiene la crisis económica para las actividades de desarrollo del Tercer Mundo. La crisis económica de 1973 señala el fin de un cuarto de siglo de crecimiento sin precedentes en la economía mundial, en el cual la renta per cápita sube anualmente a un promedio del $3 \%$ para todos los países, sin embargo, para la mitad más pobre de la población del Tercer Mundo este período trae por el contrario una declinación del nivel de vida (según el estudio de Adelman y Morris, 1973).

Las negociaciones del NOEI se hacen menos dinámicas a partir de 1977, cuando los países industrializados comienzan a superar el impacto global de la crisis y prefieren abocarse a solucionar sus problemas particulares.

Durante la primera mitad de la década pasada casi todos los países industrializados ponen en aplicación el Sistema General de Preferencias; no obstante, sus efectos en la expansión de las exportaciones del Tercer Mundo son reducidas por la imposición generalizada de limitaciones. También es de destacar la formación de asociaciones de productores de productos básicos que, siguiendo el ejemplo de la OPEP, buscan equilibrar en estos mercados tradicionalmente dominados por los países industrializados, los beneficios para los países en desarrollo.

Las negociaciones del NOEI continúan en algunas áreas, como las de códigos de conducta sobre transferencia de tecnología y empresas transnacionales y en otras áreas se obtiene ciertos logros, por ejemplo la creación del Fondo Común de financiación para el Programa Integrado de Productos Básicos; sin embargo el Grupo de los 77, en medio de una creciente frustración por el escaso proceso global en las negociaciones, opta por preconizar una estrategia de repliegue y de búsqueda de la auto- 
suficiencia colectiva mediante la cooperación horizontal entre países en desarrollo.

A través de la década pasada continúa y se acentúa el proceso de internacionalización de la producción a cargo de las empresas transnacionales de los principales países industrializados. Los cambios en la economía internacional como el alto costo de la energía y de la mano de obra en los países industrializados, además del deterioro de los términos del intercambio de las manufacturas frente a los productos básicos, incentivan a una transferencia más acelerada de la capacidad manufacturera a algunos países en desarrollo, reservando el dominio de la tecnología y los servicios para los países industrializados. La entrada de Europa al proceso a partir del 70 hace evidente la participación de los gobiernos al lado y detrás de la formación y expansión de las empresas transnacionales. En general, la creciente intervención de los gobiernos, tanto anfitriones como del país de origen de las empresas transnacionales, para estimular o controlar sus operaciones en una coyuntura de crisis en la que aumentan los controles estatales sobre la economía; contribuye a desvanecer el mito de una economía mundial regida por las empresas transnacionales, aunque no a disminuir su importancia operativa en los mercados internacionales.

\section{La problemática actual de la coyuntura y su proyección}

En la década del 70, la inflación desplaza al desempleo como tema central de análisis dentro del sistema económico internacional. La caída del dólar ocasiona una estampida hacia el oro y los productos básicos y con ello la espectacular alza de sus precios; posteriormente el alza de los precios del petróleo generaliza la inflación y la inestabilidad en la economía mundial. Sin embargo, como las alzas de precios ocurren en medio de crecientes expectativas de bienestar de las poblaciones de los países industrializados, sustentadas en el optimismo creado por la prosperidad de la década anterior, los gobiernos en vez de adoptar medidas severas de control del gasto optan por alimentar la inflación con mayores gastos.

Los perturbadores efectos de las alzas sobre la renta nacional y la balanza de pagos motivan medidas de aislamiento en las economías industrializadas para protegerse de la inflación importada. Esto intensifica internacionalmente la recesión y crea el fenómeno de la "estanflación", una desconcertante situación de estancamiento y desempleo con inflación.

Las tentativas de acción coordinada de los países industrializados se centran en la reducción y financiamiento de los déficits derivados de 
la importación de petróleo y en combatir la "estanflación" acordando medidas de reactivación económica no inflacionarias.

Las características actuales de la economía mundial son una recesión crónica que, después de haber cedido a partir de 1977, amenaza recrudecer en 1980, grandes déficits de balanza de pagos como contraparte de los superavits de los países productores de petróleo y una situación financiera precaria del mundo en desarrollo, inclusive de algunos países de mayor desarrollo relativo, por haber incurrido en un fuerte endeudamiento al inicio de la recesión (en 1972-78 mientras que la deuda se quintuplicó para los países industrializados creció 12 veces para los países en desarrollo).

Durante la década del 80 la inflación seguirá siendo el problema principal y el nivel de los precios del petróleo un factor decisivo para su manejo. Para 1980 y 1981, por ejemplo, los países industrializados han adoptado medidas restrictivas en sus economías (similares a las que utilizaron en 1974) designadas a contrarrestar los efectos inflacionarios de la fuerte alza de los precios del petróleo decretada por la OPEP en 1979. Esto significa que la lucha contra la inflación será a expensas del empleo, del ingreso real y del ritmo de crecimiento de las economías industrializadas, el cual se pronostica alcanzarán apenas $1 \%$ en 1980-81. Sin embargo, se estima estas medidas sólo podrán atenuar de manera limitada la inflación en los próximos dos años.

A. 1985 la OCDE estima que el desempleo en los países industrializados llegará al $6 \%$ de la población activa y que las restricciones en la disponibilidad de energía serán las principales limitantes del crecimiento y el empleo. Pero además de las limitaciones que pueda imponer el abastecimiento de petróleo hay una capacidad ociosa en la industria, debido a que el potencial de producción generado en los años de prosperidad, hasta 1973 parece resultar exagerado para la capacidad de la demanda, especialmente en las industrias básicas. Sin embargo hay que recordar que los países industrializados, de manera semejante al Tercer Mundo, no forman tampoco un grupo homogéneo y que sus perspectivas económicas en esta década acusan importantes diferencias. Por ejemplo, a mediano plazo levantar la tasa de crecimiento es un problema más grave para Europa que para Japón o Estados Unidos. Debido principalmente a problemas de organización y ajuste estructural Europa, con la probable excepción de Alemania Federal, podría ver declinar su participación en el ingreso mundial y estancar los niveles de vida de sus poblaciones a 1990. En cambio Japón junto con China y el Sudeste de Asia es previsible que tengan una notable tasa de crecimiento.

Los impulsos de crecimiento económico de los países industrializados tropiezan en esta década con los obstáculos de falta de consenso 
interno y lucha por la distribución de la renta, al haberse esfumado con las convulsiones de la década pasada los últimos vestigios de los grandes propósitos que orientaban su evolución desde la postguerra, relacionados con la reconstrucción de sus economías y la recuperación de sus identidades nacionales y de sus roles internacionales, Pero la esencia de los problemas de la economía mundial es una intensa pugna a nivel internacional por la distribución de beneficios, después de haberse producido sígnificativos cambios en la distribución mun dial del poder.

En está década se desarrollarán acontecimientos en tres campos de la economía internacional cuyos resultados encierran una importancia crucial para la configuración de un nuevo esquema de poder económico entre los estados:

a) El desarrollo de áreas monetarias y su influencia sobre el acuerdo de un sistema monetario.

b) El suministro de productos básicos y sus repercusiones sobre el comercio mundial y los términos del intercambio.

c) Los patrones individuales de producción de los países industrializados y de los países en desarrollo de mayor envergadurara.

\section{Dinámica mundial del poder}

En el sistema económico internacional el poder se ejerce a distintọs ni. veles. Los patrones de inversión, comercio y consumo son impuestos por los actores con mayores recursos, quienes determinan así las estructuras del sistema. Las reglas mínimas para asegurar estabilidad, orden y cumplimiento de ciertos imperativos morales los acuerdan grupos de actores expresamente reunidos para tal fin donde nuevamente tienen mayor influencia los actores de mayores recursos, coordinando sus acciones en general para que las reglas complementen las orientaciones de la estructura. Finalmente, afectan significativamente el funclonamiento del sistema las reglas formuladas individualmente por los actores nacionales de mayores mercados respecto al comportamiento de los factores de producción, el crédito y las transacciones en general.

Merced a su mayor potencial económico, los actores de los países industrializados modelaron a su conveniencia el sistema económico internacional desde 1945 y dentro de ellos EE UU. fue la economía hegemónica. Sin embargo, a partir de la década pasada los patrones de inversión, comercio y consumo han sido también fijados en buena medida por nuevos actores, los países de la opEP y los países: en desarrollo de mayor envergadura, a través de sus excedentes petroleros y de su creciente capacidad de producción y exportación; respectivamente. Por otro lado, las reglas de juego han dejado de tener vigencia y para la tarea de acordar nuevas 
reglas un nuevo grupo numeroso de actores ha obtenido una participación parcial - el Tercer Mundo. Esto ha creado un fenómeno de difusión internacional del poder, debido a la multiplicación de los factores influyentes para el funcionamiento del sistema económico.

Los gobiernos han venido a jugar un rol preponderante en las economías industrializadas y sus tradicionales objetivos de seguridad y poder en la arena internacional se han visto considerablemente ampliados, debido a la abundancia de recursos a su disposición y a las presiones ejercidas por las expectativas materiales de las poblaciones. De la misma manera que la interdependencia de los países industrializados liga estrechamente sus políticas. internas con sus políticas exteriores, el bienestar se suma en pie de igualdad a la seguridad como objetivo de política exterior, La tradicional distinción entre "altas" y "bajas" políticas se hace relativa. La negociación internacional combina cartas económicas, políticas y aun estratégicas y no pocas veces los demás objetivos son subordinados a los objetivos económicos. Los estados apoyan sus medidas de política económica externa con toda la gama de instrumentos de política exterior y es por ello que actores de un nuevo tipo, como las Comunidades Europeas, han debido ensayar la coordinación de sus políticas exteriores para respaldar y defender los logros de sus acciones económicas en el sistema internacional.

La naturaleza de la interacción entre los gobiernos ha cambiado; ya no se trata únicamente del "estado de guerra" y de la competencia por recursos limitados; ahora se dan situaciones diversas de interdependencia que demandan a la vez acciones de competencia y solidaridad. Con la transformación de las políticas exteriores, la política internacional se ha convertido en un escenario de enfrentamiento de diversas políticas internas de los actores más poderosos, con objetivos compatibles conflictivos entre sí; la mecánica del enfrentamiento se da a través de la manipulación de las distintas cuerdas de la interdependencia por cada uno de los actores. El contexto de negociación ha cambiado también, con la multiplicación de organismos, instituciones y coaliciones de las que se valen los actores gubernamentales para sacar adelante sus objetivos, a base de compromisos e intereses comunes.

Entre los objetivos que los países industrializados desean que cumpla el sistema económico internacional, tales como eficiencia, crecimiento, pleno empleo, adecuada distribución, estabilidad de precios, calidad de vida, la seguridad económica ha adquirido singular relieve en la década pasada. En realidad la seguridad económica involucra toda un a gama de intereses: acceso seguro a los productos básicos y a mercados externos y protección frente a las dislocaciones que pueda producir la penetración de bienes, mano de obra o capital externos en la economía 
nacional. En cierto sentido, la seguridad económica no es en sí un objetivo sino una precondición para la satisfacción de intereses fündamentales; por esta razón se le concibe estrechamente vinculada a la seguridad militar y es la condición primordial que los gobiernos de los países industrializados desean establecer en las nuevas reglas y acuerdos para la economía internacional.

Podemos fácilmente inferir de todo esto que la economía internacional no va a estar dominada en la década del ochenta por las empresas transnacionales ni por burocracias internacionales, tal como solían predecir los futurólogos de la década del sesenta. Tampoco va a desarrollarse en un contexto dual Norte-Sur, pues varios países en desarrollo ya tienen una importante participación y acceso a las fuentes del poder económico. Los principales actores seguirán siendo los gobiernos, desenvolviéndose en complejos escenarios, empleando sistemas de negociación y coalición múltiples y utilizando instrumentos diversos del poder económico, político y estratégico.

Para pensar en el futuro inmediato del sistema internacional es útil concebirlo analíticamente, dividido en tres subsistemas que comprenden respectivamente las interacciones de las dos superpotencias y sus aliados, las de los países industrializados entre sí y las de los países industrializados con los países en desarrollo. En el primer subsistema funciona la política de détente, en el segundo una estrecha interdependencia y en el tercero tienen lugar, en distintos planos, el diálogo NorteSur y la intemacionalización de la producción. Los subsistemas correspondientes a las interacciones de los países en desarrollo entre sí y a la esfera de los países socialistas no van a ser enfocados en este trabajo.

\section{LÍNEAS GENTRALES DE INTERACGIón Y TENDENCIAS POLITICO-ECONOMICAS}

\section{Interdependencia}

Las favorables condiciones establecidas por el sistema de Bretton Woods para el desarrollo de las transacciones económicas internacionales propiciaron el fortalecimiento de una red de vinculaciones entre las economías industrializadas. Las transacciones económicas, con su secuela de costos y beneficios para los participantes, fueron creando un marco común de intereses el cual fue progresivamente tomado en cuenta por las políticas económicas de los gobiernos. La sensibilidad y vulnerabilidad mutua determinada por las interconexiones de las economías impulsan la interdependencia de las políticas.

La interdependencia creció durante un largo período de prosperidad 
para el mundo industrializado, mientras Estados Unidos fungía de líder indisputado de la economía liberal, sin ningún desafío a su hegemonía y todas las economías disponían de energía barata. Cuando Estados Unidos quiso cambiar las bases de su hegemonía, ésta fue contestada por los demás participantes, quienes plantearon una renegociación cabal de las reglas de juego, las líneas de interdependencia se estancaron y se desató el conflicto a través de ellaś. La crisis de la energía agravó la situación, forzando a los gobiernos a aislar las economías. Aumentó el proteccionismo y crẹció la sombra de una nueva era de mercantilismo en la economía mundial, que aún no se desdibuja.

\section{Neomercantilismo y Regionalización de la}

Economía Mundial

El proteccionismo ha sido de distintas maneras una regla en las relaciones económicas internacionales en la época moderna. Las razones más comunes para su adopción son el mantenimiento del empleo y el aumento de la prosperidad nacional, aun a expensas de otros estados; ambas son actualmente preocupaciones centrales de los gobiernos.

En la medida que el mercantilismo consiste básicamente en otorgar prioridad a los objetivos económicos nacionales sobre las consideraciones globales de eficiencia del sistema económico internacional, un nuevo mercantilismo entrañaría la adopción sistemática de restricciones al movimiento de bienes, capital y mano de obra, en el supuesto de que tienen menor importancia las ganancias que pueda tener el libre intercambio que las perturbaciones negativas que estos flujos incontrolados pueden causar en la economía nacional. Por otro lado, la pérdida de autosuficiencia nacional es vista como una fuente de inseguridad política y económica y de conflicto, en una perspectiva Keynesiana. De acuerdo con esta concepción, la economía internacional en esta década podría caracterizarse por una intensa competencia por fuentes de abastecimiento de productos básicos, mercados y plazas de inversión vinculada con el forjamiento de una nueva configuración del poder económico mundial y la consolidación del orden correspondiente.

El período 1945-1973 quedaría como un intervalo excepcionalmente largo de libre intercambio en el cual, entre otras cosas, la moderada intervención estatal motivó que las acciones incoordinadas de la libre empresa llevaran a la economía mundial a una situación de "estanflación" no concebida por la teoría económica.

Desde fines del siglo pasado uno de los problemas centrales de las relaciones internacionales ha sido el de organizar una economía industrial de alcance mundial. La pugna imperialista y comercial que se desa- 
rrolló a comienzos de este siglo y culminó en la primera guerra mundial tenía este motivo. Durante las décadas del 20 y el 30 el problema se mantuvo irresuelto ya que las demandas alemanas y japonesas de participación equitativa en los beneficios del sistema no fueron atendidas. Desde antes de acabar la segunda guerra mundial los EE.UU. consideraban como problema central de la postguerra la reorganización del sistema económico internacional. El orden económico norteamericano de la postguerra se mantuvo incuestionado mientras convino a todos los países industrializados en el contexto de la reconstrucción, de la guerra fría y de la clara supremacía estadounidense. Pero cuando Nixon anuncia unilateralmente en 1970 el reajuste del sistema por los decrecientes beneficios que reporta a EE.UU., el antiguo problema de organizar la economía mundial entre competidores en pie de igualdad vuelve a ponerse sobre el tapete en toda su dimensión.

La perspectiva del mercantilismo se vincula con la regionalización de la economía mundial. El sistema económico internacional está siguiendo una evolución que puede interpretarse ya hacia la fragmentación eñ bloques regionales. De acentuarse esta tendencia, el comercio, los arreglos monetarios y la inversión aumentarían su concentración a nivel regional. La regionalización se consolidaría en principio alrededor de las cuatro grandes potencias económicas, a saber: Estados Unidos, Europa, Japón y la Unión Soviética. Los superbloques en formación podrían traer conflicto al sistema internacional con sus pugnas por mercados, fuentes de abastecimiento y plazos de inversión, pero también podría ocurrir que el efecto más importante de la regionalización fuera estabilizar las relaciones económicas internacionales y echar las bases de un nuevo sistema económico que satisfaciera las exigencias de seguridad económica de las potencias.

Para los países industrializados esta posibilidad constituiría un término medio entre la hegemonía estadounidense de las décadas anteriores y la indeseable perspectiva de un conflicto prolongado entre las economías más poderosas, evitán'dose el enfrentamiento de éstas con la provisión de esferas de influencia. Desde mucho tiempo atrás cada una de las cuatro potencias fortalece las relaciones económicas con los países de sus regiones contiguas; un ejemplo ilustrativo lo constituyen las convenciones de Lomé entre las Comunidades Europeas y los países del grupo ACP, que sientan las bases para una vinculación estructural y duradera de las economías de ambos grupos. El caso de América Latina como conjunto, sin embargo, no es muy claro, pues en las últimas décadas se ha debilitado algo la presencia estadounidense en la región por el fortalecimiento de las relaciones económicas con Europa y el Japón. Esta situación. excepcional es explicable por las características de desa- 
rrollo intermedio de los países latinoamericanos, que incluyen entre sí varias economías de gran envergadura con reales emergentes en la economía mundial, así como por la política de "presencia discreta" de EE.UU. en la región durante gran parte de la década pasada.

El mayor obstáculo previsible para la concreción de la perspectiva mercantilista-regionalista lo constituye la dependencia estratégica de dos de las potencias (Europa y Japón) del poder americano, que limita sus posibilidades de acción autónoma. Este obstáculo no lo podrían salvar ellas directamente en la próxima década buscando algún tipo de paridad con las dos superpotencias, pues éstas les llevan muchos años de ventaja en el diseño, fabricación e instalación de armamento, pero sí robusteciendo en el caso europeo la détente con la URSs y en el caso japonés la cooperación. con la China. De todas maneras, quedarían los problemas de la aceptación por las potencias de las cargas económicas y militares ajenas al rol de custodio y gendarme de sus regiones (tal como en cierta forma actúan las Comunidades Europeas, a través de Francia en el Africa Negra) y el eventual rechazo radical de su hegemonía por parte de algunos países de la región como sería presumible en el caso de la hegemonía japonesa en el Sudeste Asiático.

\section{Trilateralismo y coordinación de los países industrializados}

Creada por iniciativa de David Rockefeller en 1973, la Comisión Trilateral y su doctrina de la "gestión de la interdependencia" representan un esfuerzo por mantener y reestructurar la relación entre EE. uU., Europa y Japón ante la amenaza del nuevo mercantilismo. El trilateralismo refleja la opinión de intereses financieros involucrados en esta relación triangular y aboga por la creación de una "comunidad de naciones desarrolladas" que coordine sus acciones para abocarse a problemas y áreas de interés común. Sostiene que si los países industrializados no son capaces de hallar soluciones para sus problemas económicos comunes las repercusiones de éstos en las esferas política y estratégica harán que su supremacía mundial peligre frente al bloque comunista y frente a las demandas igualitarias de los países en desarrollo.

La Trilateral encuentra que al lado de una falta de deseo de EE.UU. de contlnuar siendo el líder del mundo occidental están la incapacidad de Europa y Japón para asumir este rol, preconizando como única alternativa viable una estrategia de cooperación. En este sentido propugna una suerte de. "ultraimperialismo" en vez de las rivalidades imperialistas que podría traer consigo el nuevo mercantilismo.

En el campo estratégico el trilateralismo refleja la crisis de la postura 
de fuerza de EE.UU. y de sus potencialidades para la acción unilateral, la cual sobrevino como secuela de la Guerra de Vietnam. La nueva percepción de EE.UU. le hace reconocer la necesidad de compartir el peso de la defensa de Occidente con sus aliados.

El Trilateralismo concibe al sistema capitalista en vías de transformación mediante el forjamiento de una nueva división internacional del trabajo, en la cual el mundo en desarrollo asume la exportación de manufacturas mientras que los países industrializados mantienen la hegemonía con la exportación de bienes de capital y la provisión de servicios al resto del mundo.

Las empresas transnacionales desempeñan un rol clave dentro de esta concepción, pues valiéndose de la asociación con ellas los países en desarrollo pueden penetrar los mercados del mundo industrializado. La industrialización de los países en desarrollo resulta además una fórmula de "apaciguamiento" para el Tercer Mundo, que se complementa con el enganche de algunos países en desarrollo de mayor peso para el desempeño de roles decisorios en la gestión de la economía internacional.

Con la asunción de Carter al poder en 1976, el trilateralismo gana el favor de la administración estadounidense. Un año antes, las preocupaciones de la gestión de la interdependencia habían encontrado eco en los mandatarios de Ảlemania Federal y Francia, quienes convencieron al presidente Ford para que convocara a una Reunión Cumbre de los principales países industrializados con el fin de examinar la coordinación de políticas económicas encaminadas a salvar la crisis.

Desde 1975 se han realizado seis reuniones cumbre, en las cuales se ha buscado asegurar niveles adecuados de crecimiento e intercambio en la economía mundial. Las discusiones se han centrado básicamente en torno al dólar y a la necesidad de que EE.UU. controle sus déficits externos y dé solidez y estabilidad a su moneda a fin de salvaguardar los elementos sobrevivientes del sistema monetario internacional. Hasta 1977 los tópicos coyunturales predominantes fu'eron el fortalecimiento del sistema financiero internacional ante las presiones creadas por el alza de los precios del petróleo y el control de la inflación y del proteccionismo, así como la obtención de algún grado de coordinación del Norte para la Conferencia Norte-Sur de 1977.

En 1978 los países europeos plantean el reordenamiento monetario europeo para acabar su dependencia del dólar y dejar de sufrir los efectos de su continua devaluación (entre 1970 y 1978 el dólar pierde más del $50 \%$ de su valor frente al marco alemán). El proyecto obedece al deseo europeo de controlar la inflación y contar con un patrón monetario propio que permita reactivar la acumulación de capital y sacar al 
capitalismo europeo de la crisis que le impide acercar sus tasas de crecimiento a las de Estados Unidos y Japón. Sin embargo; el Sistema Monetario Europeo, que en la práctica es un área monetaria del marco, tiene otras implicancias que provocan honda suspicacia en los EE.UU. Contando con una moneda de reserva europea y con las reservas alemanas (las cuales duplican a las de EE.UU.) para financiar los déficits de los países europeos y asegurar la estabilidad de sus signos monetarios, no sólo se cuestiona el liderazgo americano en el terreno monetario, ejercido a través del dólar y el FMI, sino también en los ámbitos político“ y económico en general.

En cuanto a la reactivación de la economía mundial, el acuerdo que se logra en 1978 entre las tres potencias capitalistas mundiales, EE.UU., Alemania Federal y Japón es que el primero reduzca sus importaciones de petróleo (las cuales desde 1972 acusan un marcado incremento con relación al petróleo producido internamente) para sanear su balanza de pagos y estabilizar el dólar y, a cambio, Alemania aumente el gasto fiscal y la demanda en su economía y Japón restrinja las exportaciones y estimule las importaciones para reducir el superávit de su balanza comercial. El principal inconveniente para el cabal cumplimiento de este acuerdo reside por una parte en las segundas intenciones de Alemania y Jàpón al pedir la limitación de las importaciones estadounidenses de petróleo, las cuales apuntan a frenar el crecimiento económico de Estados Unidos y por otra parte en el rol instrumental que poseen para EE.UU. las fluctuaciones del dólar para mejorar su competividad en los mercados internacionales.

En la cumbre de Tokio de 1979 el foco de atención es la energía, debido a la reciente alza decretada por la OPEP, acordándose extender la restricción de las importaciones de petróleo a las Comunidades Europeas y Japón y fijándose cuotas por países hasta 1985, además de coordỉnar programas de investigación sobre fuentes alternativas de energía y bosquejar medidas conjuntas para evitar se puedan repetir crisis de energía como la de 1973-74. En la reciente reunión de Venecia (1980) se comprueba la imposibilidad de cumplir las metas de consumo de petróleo decididas el año anterior, pero se completa un programa de prioridades y actividades conjuntas en el campo de la energía hasta 1990.

La problemática que se plantea en las cumbres es la de una economía mundial dividida por barreras arancelarias y políticas en bloques y áreas monetarias, que limitan la expansión del intercambio y frenan el crecimiento. Por su nivel de desarrollo y sus medios de pago solamente EE. UU., Europa o Japón pueden cambiar esta situación, reactivando el intercambio entre sí y con otros grupos de países mediante un financiamiento prudente que no vulnere su propia solidez. 
Existe una solución de corte Keynesiano, propugnado por el Informe Brandt, de financiar, mediante una transferencia masiva de recursos, la recuperación del Tercer Mundo para que ésta revierta benéficamente en las economías industrializadas a través de un aumento del intercambio Norte-Sur. Esta propuesta parece no haber encontrado mayor acogida en el "directorio" de los países industrializados. Enfocando el asunto desde un ángulo distinto, los países industrializados se limitan a advertir (1980) que durante esta década la OPEP deberá compartir una mayor proporción de la asistencia al Tercer Mundo. Esta actitud de los gobernantes del mundo industrializado contrasta no sólo con las opiniones del Informe Brandt sino que ni siquiera parece estar en línea con las de la Comisión Trilateral respecto a la naturaleza evolutiva del sistema capitalista. El 'contraste puede explicarse por la dificultad que encuentran los gobernantes para contemplar políticas como las que implica la concesión de beneficios al Tercer Mundo por sus consecuencias negativas a corto plazo sobre grandes sectores de la población, a despecho de su previsible efecto positivo a mediano y largo plazo en la economía.

Un intento de mayor envergadura de eliminar las barreras que limitan el intercambio mundial en el plano comercial culminó, después de seis años de negociaciones, en la Ronda de Tokio. El resultado ha sido la formulación de nuevas reglas orientadas a asegurar la liberalización del comercio internacional en lo que resta de este siglo.

En realidad la incógnita de saber si la economía mundial derivará hacia el mercantilismo y la formación de bloques regionales o mantendrá un nivel de integración y coordinación que permita sobrevivir un sistema económico de alcance global quedará despejada en gran medida con el grado de cumplimiento que se dé a las normas para el comerçio.internacional acordadas en la Ronda de Tokio.

No parece factible que los gobiernos de los países industrializados, en tanto persista la recesión, abandonen el proteccionismo, enderezado principalmente hacia las manufacturas de los países en' desarrollo. Aparte de los problemas de ajuste, que se hacen más dificiles en esta situación, hay otras razones, por ejemplo de seguridad, para que los estados deseer mantener una capacidad autosuficiente en las industrias básicas. También por razones tecnológicas, para mantenerse en la vanguardia en investigación y desarrollo en ciertas ramas, es previsible que se conserve la protección de industrias como la de artefactos electrónicos.

Para proteger sus industrias los países industrializados pueden recurrir al expediente de fomentar arreglos bilaterales de carácter privado entre las industrias de exportación de los países en desarrollo y sus industrias perjudicadas, los cuales no son afectados por las nuevas normas. No en vano las Comunidades Europeas, que son las que más utilizan esta 
modalidad de restricción de las importaciones, se opusieron durante la Ronda de Tokio a alcanzar acuerdos con los países en desarrollo de mayor envergadura respecto a la selectividad y publicidad que debería acompañar estos arrègos.

Por otro lado, hay que considerar que las reglas de Tokio difícilmente tendrán algún impacto importante en áreas de comercio tales como los de productos agrícolas y minerales y en la de manufacturas como los textiles, las cuales se rigen por acuerdos entre productores y consumidores o han experimentado un proceso de cartelización e interveńción conectado con las demandas de un NOEI. Tampoco serán afectados los regímenes especiales de comercio regional que constituyen una importante tendencia actual y que escapan a las normas de Tokio.

En virtud de estas dificultades se ha formulado el pronóstico de que recién hacia 1985, cuando posiblemente se supere la recesión mundial, las reglas de Tokio podrían comenzar a ser puestas en vigencia.

\section{Détente}

La détente, que comienza a insinuarse en lo político y estratégico después de la crisis de los misiles en Cuba (1962), adquiere una dimensión económica en la década pasada, con la suscripción de acuerdos y contratos comerciales entre Estados Unidos y la URSS, como en general entre los países del bloque occidental y los del comunista y con el consiguiente incremento del intercambio Este-Oeste.

Desde el comienzo, EE.UU, trata de consolidar la distensión estratégica con su acercamiento a la URSs, subordinando la cooperación económica a objetivos políticos y de seguridad. En cambio la URss muestra intereses esencialmente económicos por la nueva relación, la cual representa la posibilidad de adquirir tecnologías occidentales necesarias para mantener y completar el proceso, de modernización de su economía. Esta diferencia de perspectiva queda en evidencia tempranamente en la década pasada con la renuencia de la URSS a modificar ciertas líneas de política exterior o a otorgar concesiones de otra índole en el marco de la cooperación económica. Pero el contraste parece agudizarse con la cadena de intervenciones directas e indirectas de la URSs, durante los últimos años del 70, en Angola, Etiopía, Yemen, Cambodia y especialmente Afganistán.

La agresividad de la política exterior soviética encuentra una moderada respuesta en los Estados Unidos, la cual en la percepción del bloque occidental constituye otra línea de repliegue del poder americano a nivel mundial. El pasivo rol de EE.UU. en la caída del Shah de Irán confirma su debilitamiento como potencià mundial. Pero la invasión de Afganistán trae la sacudida más fuerte a la creencia en el poder, en la resolución y en la 
capacidad de respuestas americanas, que fue el pilar fundamental del orden de la postguerra.

Frente a la vacilación e impotencia estadounidense, Europa se ve obligada a llenar el vacío de poder asumiendo un nuevo rol en las relaciones Este-Oeste. Los paísés de las Comunidades Europeas y muy señaladamente Alemania Federal, al mismo tiempo que reafirman su solidaridad con el bloque occidental y replantean su rol'para la defensa del mismo, revelan bases para la détente con el bloque comunista que no son idénticas a las que posee Estados Unidos.

El compromiso europeo con la détente es mucho más fuerte que el norteamericano. En lo político, Europa no puede confiar como antes en la defensa norteamericana del continente y por lo tanto juzga necesario un marco consistente de cooperación y mutuo beneficio con el Este que dificulte la alternativa bélica. En lo económico, Alemania, Francia e Italia (al igual que Japón en el Lejano Oriente) tienen relativamentte mayor comercio con el bloque socialista que los EE.UU. y en las presentes circunstancias no quieren ver disminuir su volumen. En lo cultural, Europa Occidental ha visto resurgir un sentimiento de identidad con los países de Europa Oriental, por encima de la artificial barrera política.

Estas consideraciones cobran una vigencia más intensa en el caso de Alemania Federal, la que desarrolla desde 1969 su "Ostpolitik" como un área de "alta política", combinando en ella la expansión del comercio con la cooperación a largo plazo y el interés de mejorar su situación en un territorio dividido por la presencia del bloque soviético. Alemania es largamențe el primer exportador occidental de manufacturas a la uRss y a la vez recibe de ella materias primas, incluyendo $25 \%$ de su gas natural importado y $40 \%$ de sus importaciones de uranio enriquecido.

En realidad Alemania se ha convertido a fines de la década pasada en el tercer estado mundial, después de las superpotencias, por su extraordinario poder económico y su nuevo rol político en Europa y el resto del mundo. Este hecho no ha podido ser advertido cabalmente por la comprensible reticencia alemana a traducir su poder económico en poder político (únicantente modificada con el vacío de poder ocasionado por la actitud de Estados Unidos) y por su preferencia por el condominio germano-francés en las Comunidades Europeas, en el cual Francia suele aparecer a cargo de las iniciativas comunitarias.

Sin embargo, el hecho es que Alemania ha vuelto a ser un actor de primera línea en Ia esceria mundial (como lo reconocieran los "tres grandes" de Occidente al invitarla a la reunión de Guadalupe en 1979) y que la "cuestión alemana", el interrogante respecto al rumbo de este país, vuelve a adquirir actualidad. Investida del coestrellato en el Sistema Trilateral, Alemania mantiene una relación especial con Estados Unidos que el po- 
der económico alemán en medio de la recesión general ha vuelto más equilibrada, tornando su permanencia en la alianza occidental un asunto más de elección que de necesidad. En las nuevas circunstancias internacionales Alemania ha dejado su rol de barrera para el mundo comunista y ha asumido el rol de puente entre los dos bloques.

Europa, dirigida por el eje Franco-Alemán, ha sido empujada por las circunstancias a tomar un rol central y activo en la política internacional. Las dudas acerca de la capacidad de EE.UU. para su defensa y una diferente valorización de la détente la llevaron a percibir y reaccionar de manera distinta a EE.UU. ante la invasión de Afganistán. Viendo este acontecimiento no como una ofensiva global del comunismo que pùsiera en peligro inminente el equilibrio Este-Oeste sino como una amenaza para algunos regímenes inestables próximos a la URss, se ha propuesto un programa de acciones que no sólo asiste a los estados más vulnerables a las presiones soviéticas sino que también incide en las raíces de la inestabilidad en el Cercano Oriente: el conflicto árabe-israelí.

En este sentido la política exterior y la asistencia económica de Francia, Inglaterra y Alemania ha sido reorientada prioritariamente a los regímenes más vulnerables de Asia, Africa y el Cercano Oriente, las Comunidades Europeas han concluido un acuerdo de cooperación con los países de ASEAN con un claro propósito político y en la última cumbre de Venecia se presentó por primera vez una iniciativa europea para resolver el problema árabe-israelí.

De esta manera, la iniciativa europea evita hasta ahora la polarización del mundo y el resurgimiento de la "guerra fría" en toda su dimensión, aunque se inserta en una revalorización de los objetivos políticos y estratégicos frente a los objetivos puramente económicos que podría matizar la pugna por el poder económico en esta década.

Evidentemente, para el futuro de la détente el factor principal será el comportamiento de la URss, el cual resulta de muy difícil predicción por varias circunstancias. A corto plazo deben producirse cambios fundamentales en la composición de la dirigencia soviética. La pugna correspondiente inrroduce desde ahora factores imponderables en la política exterior soviética, Ia cual podría mostrar nuevas tendencias una vez realizados los cambios, si se tiene en cuenta el debilitamiento del aparato imperialista soviético y el bajo rendimiento de la economía así como sus críticas perspectivas. Por lo pronto ya se ha planteado un nuevo expansionismo, en una reformulación de la doctrina Brezhnev de política internacional (1980) que señala el derecho de la uRss a ayudar a la consolidación de gobiernos comunistas fuera del bloque soviético.

Para mediados de esta década el suministro de energía se tornará una limitación crítica para el crecimiento económico de la URSS. Esta 
perspectiva y la reciente invasión de Afganistán hacen converger las expectativas de los mayores países industrializados al área del Golfo Pérsico, de la cual obtienen la mayor parte de su petróleo y donde existen regímenes de precaria estabilidad que podrían sucumbir a las presiones soviéticas.

\section{Diálogo Norte-Sur}

Después de un comienzo más o menos auspicioso en el seno de las Naciones Unidas y en la IV UNCTAD (1976) el diálogo Norte-Sur, orientado a establecer un Nuevo Orden Económico Internacional, se estanca y se "producen impasses en la mayor parte de los temas de la agenda de negociación.

En cuanto al acceso al mercado de los países industrializados en la IV UNCTAD el Norte acordó suprimir las restricciones y mejorar el Sistema General de Preferencias, sin reclamar concesiones recíprocas y sin discriminar el comercio de manufacturas. Pese a esto el proteccionismo de los países industrializados no ha disminuido desde 1976.

En el campo de la transferencia de recursos, que incluye asistencia al desarrollo, problemas de la deuda externa y mayor participación de los países en desarrollo en los organismos económicos internacionales, el progreso ha sido casi nulo. Igualmente las demandas de los países en desarrollo no han sido atendidas en las negociaciones de reforma del sistema monetario internacional.

Respecto a la transferencia de tecnología el único tema sobre el cual continúan las negociaciones es el de la elaboración de un Código para la Transferencia de Tecnología, pese a que no se pudo llegar a un acuerdo en la $\mathrm{V}$ UNGTAD, debido a la oposición de los países industrializados a que el Código tenga fuerza jurídica obligatoria.

$\mathrm{El}$ comercio de productos básicos parece ser una de las pocas áreas del diálogo Norte-Sur apropiada para desarrollar negociaciones fructíferas por el momento. En el marco del Programa Integrado de Productos Básicos, concebido para mejorar la estructura de estos mercados para los países en desarrollo, con una cobertura de 18 productos, se viene llevando a cabo las negociaciones por productos con miras a lograr sendos convenios multilaterales o modificar los convenios existentes.

En marzo de 1979 se aprobaron las normas básicas del Fondo Común de financiamiento de las actividades del Programa Integrado llamado a dar impulso a las negociaciones por productos. Este mecanismo fue diseñado por la Secretaría de UNCTAD pero implementado en la versión favorecida por los países industrializados por lo cual resulta adecuado solamente para estabilizar hastà cierto punto los precios de los productos básicos, pero no para asegurar su regular incremento. La preponde- 
rancia de la propuesta de los países industrializados respecto al Fondo Común se explica por la división que hubo entre los países en desarrollo en el curso de las negociaciones.

En el campo de las empresas transnacionales, la regulación de cuyas actividades reclama el Tercer Mundo, se trata igualmente de elaborar un código de conducta que sirva de base para contratar la participación de estas empresas en las economías nacionales de manera que contribuyan al desarrollo, y controlar los efectos negativos de su funcionamiento.

Los países industrializados argumentaron que tal código sólo sería aceptable si incluyera también prescripciones para el tratamiento de las transnacionales por los países anfitriones y los países de origen. En este sentido señalaron elementos que resultan prerrequisitos para un "clima favorable" para la inversión, incluyendo una adecuada protección de la misma. En este punto han surgido problemas derivados del concepto de soberanía nacional de los países en desarrollo, el cual no es compatible con la vigencia del derecho internacional para normar actividades relacionadas con los recursos naturales o la economía nacionales. Otro punto de controversia, como en el caso del Código para la transferencia de tecnología, es la fuerza jurídica obligatoria del instrumento, el cual para muchos países industrializados debe ser de acatamiento voluntario por las Transnacionales al igual que las "Pautas de Comportamiento para las Transnacionales" elaboradas por la OGDE y la "Declaración de Principios sobre las Transnacionales y la Política Social" de la orr.

En este contexto es importante señalar el reciente desarrollo de iniciativas prácticas de los países industrializados con el fin de asegurar regímenes favorables y protección para sus inversiones en el Tercer Mundo, en concordancia con su propuesta en el marco del diálogo NorteSur.

Se trata de iniciativas para las inversiones mineras cuyos "riesgos políticos" en los países en desarrollo constituyen un grave problema para las economías industrializadas que puede poner en peligro su abastecimiento de productos esenciales en esta década (Europa deberá quintuplicar su inversión minera para importar el $30 \%$ de los minerales que consume, mientras que Japón deberá importar un $95 \%$ de los mismos). Las ideas básicas de estos arreglos se encuentran en documentos de las Comunidades Europeas y en el proyecto norteamericano de un Banco Internacional de Recursos (1977) y los arreglos han sido formalizados entre los países de la C.E.E. y los del grupo ACP. Mediante un tratado bilateral con el país de origen de las inversiones, el país receptor se compromete a respetar los contratos de inversión, acepta un seguro contra los riesgos no comerciales de la misma y el arbitraje externo para posibles disputas; a cambio recibe 
financiamiento adicional para otros proyectos mineros. El arbitraje, seguro y asesoramiento están a cargo de instituciones internacionales. El Informe Brandt recomienda la adopción de este tipo de arreglos.

\section{Perspectivas del Diálogo Norte - Sur}

Desde 1977 el clima favorable para las negociaciones Norte-Sur cambió y se debilitaron las presiones sobre.los países industrializados para otorgar concesiones a los países en desarrollo. En primer lugar aquéllos comprendieron que si bien los temas del NOEI, especialmente aquellos relacionados con los productos básicos, despertaban el entusiasmo político de los países en desarrollo, los proyectos específicos en discusión difícilmente contaban con su total apoyo. Esto pareció quedar en evidencia en la $\mathrm{V}$ UNCTAD cuando el Grupo de los 77 presentaba voceros regionales en cada negociación mientras los países industrializados mantenían en general unidad en las negociaciones. La diferencia de niveles de desarrollo dentro del Tercer Mundo y su acelerada diferenciación èn la década pasada explica en gran medida este fenómeno. En segundo lugar el impacto de la crisis del petróleo se fue atenuando, merced al reciclaje de los petrodólares y al ajuste de las economías industrializadas al nuevo precio del petróleo; con ello fue desapareciendo la extraordinaria urgencia del mundo industrializado por entenderse con la OPEP aun al costo de realizar concesiones a otras demandas del Tercer Mundo.

En tercer lugar, las perspectivas de nuevos carteles de los países en desarrollo en los mercados de productos básicos fueron desdibujándose al evaluarse las dificultades inherentes a la cartelización en distintos mercados, con lo cual se fue desvaneciendo el llamado "poder dẹ los productos básicos" del Tercer Mundo.

En cuarto lugar, los problemas de la recesión y del manejo económico cobraron tales dimensiones que la resolución de los conflictos entre los mismos países industrializados opacó el tema de las negociaciones Norte-Sur. En realidad, aparte de las negociaciones para la creación del Fondo Común del PIPB y algunas tratativas respecto a asociaciones de productos básicos (y códigos de conducta), todo el período posterior a la Conferencia Norte-Sur (1977) lo han dedicado los países industrializados a negociar entre ellos la reforma del sistema monetario y la revisión de las normas de comercio internacional. Para muchos observadores el diálogo Norte-Sur quedó reducido a una confrontación de poder entre la OPEP y los países industrializados y una pugna entre el proteccionismo del Norte y la agresiva exportación de manufacturas de algunos países en desarrollo.

Ante la relativa indiferencia de los países industrializados en el diálo- 
go Norte-Sur el Grupo de los 77 decide replegarse y promueve una estrategia de desligamiento de la economía internacional y de fomento de la autosuficiencia colectiva para el Tercer Mundo.

La autosuficiencia que el Tercer Mundo opone al mercantilismo de los países industrializados propugna depender fundamentalmente de los propios recursos y disfrutar de una capacidad autónoma para la fijación de objetivos y la adopción de decisiones. Implica la aceptación del comercio y la cooperación en la medida en que reportan beneficios mutuos y subraya la satisfacción las necesidades básicas de la población. Admite la transferencia de tecnologías aunque enfatiza la adaptación y generación de tecnologías propias.

En un sentido más restringido, la autosuficiencia se entiende como autosuficiencia alimentaria. En este sentido, es lamientable. encontrar que los países en desarrollo, por el contrario, han disminuido sus coeficientes de autosuficiencia en las dos últimas décadas y que el pronóstico de la OCDE al año 2000 es de un Tercer Mundo aún más dependiente. de ciertos países industrializados en cuanto a alimentos, debido a la insuficiente productividad de su agricultura y a sus tasas de crecimiento. demográfico.

La autosuficiencia colectiva en su concepción más amplia encuentra su expresión en la cooperación entre países en desarrollo, la cual fomenta y organiza activamente en las esferas económica y técnica el Grupo de los 77 en los últimos años.

La suerte de las negociaciones Norte-Sur en la década del 80 dependerá de los teinas que elija el Grupo de los 77, de los programas que proponga y sobre todo del respaldo interno que pueda conseguir para sus posiciones.

Si la elección de los temas se relaciona adecuadamente con la coyuntura económica de los países industrializados y con sus percepciones de la interdependencia en la economía mundial, podría haber progreso. En los campos financieros y de comercio se percibe actualmente una clara conciencia en los países industrializados, de que la solución de sus problemas no podrá ser duradera si se limita a arreglos entre ellos. La interrelación y la mutua dependencia de los mercados de capitales es muy grande y su creciente vinculación con los países en desarrollo los hace vulnerables a la evolución de sus economías, de manera que los problemas financieros del. Tercer Mundo tendrán significativas repercusiones en las economías in dustrializadas.

En comercio, los países en desarrollo constituyen actualmente importantes mercados para muchos países industrializados. En 1978 los países en desarrollo compran el $20 \%$ de las manufacturas de los países industrializados o sea el doble de lo que compran Estados Unidos y Japón 
juntos. Por otro lado, las importacionès de manufacturas desde algunos países en desarrollo, que originan graves perjuicios para grupos de productores en los países industrializados, resultan al mismo tiempo beneficiosas para muchas de sus empresas comerciales y para los consumidores. En verdad la gran escala de los problemas de ajuste de las economías industrializadas a los flujos de manufacturas de los países en desarrollo constituye para ellas un motivo suficiente de interés para negociar acuerdos con éstos.

En consecuencia, dadas las perspectivas de la economía mundial y la coincidencia de intereses con los países industrializados en cuanto a finanzas y comercio, podría preverse que los países en desarrollo tendrán oportunidades para formular nuevas propuestas de negociación Norte-Sur en estos campos, las cuales encierren beneficios mutuos y por lo tanto resulten aceptables para el mundo industrializado.

En el campo de los productos básicos es previsible que además de los arreglos por productos individuales se pueda llevar adelante negociaciones en otros aspectos. El desarrollo y resultado de estas negociaciones dependerá fundamentalmente del grado de solidaridad que muestren en cada caso los paises productores del Tercer Mundo, sobre la base de una distribución equilibrada de los costos y beneficios entre ellos y de la interdependencia que puedan alcanzar en cuanto a producción e inversión. Con un alto grado de solidaridad entre sí sería factible que los países en desarrollo negociaran con éxito con los países industrializados, aun en situaciones en las que a corto plazo los beneficios de una parte deben ocurrir a expensas de la otra. En un contexto de relativa paridad en poder de negociación una situación de discordia o enfrentamiento puede perjudicar a todos por igual.

La posibilidad de un reajuste más o menos ordenado del sistema económico internacional es un objetivo muy valioso para los países industrializados, ya que el actual sistema demuestra tener un funcionamiento deficiente e insatisfactorio aun para ellos. La reforma del sistema con un nuevo conjunto de reglas e instituciones que protejan en mayor medida los intereses de los países en desarrollo se les presentaría indudablemente como una mejor perspectiva que la anarquia del sistema económico internacional o la consolidación del repliegue del Tercer Mundo.

Sin embargo, la pregunta crucial que surge es, ¿hasta qué punto está en capacidad el Tercer Mundo de crear anarquía en el sistema económico internacional o de consolidar su repliegue como forma de presión sobre los países industrializados en caso de que acentuaran su actitud de indiferencia hacia el diálogo Norte-Sur?

La unidad del Tercer Mundo que, como hemos visto, es importante para aumentar su poder de negociación, sería sometida a una prueba aún más 
severa si se tratara de adoptar actitudes solidarias de fuerza para presionar al Norte a retomar las negociaciones.

El desligamiento del Tercer Mundo de la economía internacional, que hasta ahora no ha avanzado mucho del nivel de postura política, sólo sería viable si se contara con el apoyo financiero de los países de la OPEP, los cuales tendrían que decidir conectar en mayor grado sus economías con las del resto del Tercer Mundo. Tal vinculación sería posible si los países de la OPEP, por un lado, otorgaran una alta prioridad a mantener el respaldo del Tercer Mundo en su confrontación con los países industrializados, la cual promete ser muy seria en el curso de esta década y, por otro lado, reconsideraran los beneficios de una mayor inversión en el Tercer Mundo, como alternativa a la inversión en los países industrializados, donde la continua devaluación del dólar reduce progresivamente el poder adquisitivo de sus excedentes.

La implementación de las nuevas normas de comercio internacional constituirá probablemente el desafio más poderoso para la solidaridad del Tercer Mundo. Los beneficios de liberalización del intercambio que ellas traen sólo serán accesibles a los países que suscriban su aceptación. Los países en desarrollo han rehusado suscribirlas, por la insuficiencia del tratamiento especial acordado para ellos. Sin embargo, la forma más segura de acceso a los mercados del Norte que tendrán los países en desarrollo exportadores de manufacturas será a través de la adhesión a estas normas y a los acuerdos especiales concomitantes. Este acceso resiste para los países en desarrollo industrializados una significación mucho mayor que los beneficios del Programa Integrado de Productos Básicos.

Estos países tenarán que poner en la balanza sus intereses económicos de corto y mediano plazo, ligados al mantenimiento de las ventas a los mercados de los países industrializados, en condiciones menos favorables pero aún altamente competitivas, al lado de sus intereses políticos y económicos de más largo plazo, asociados con la causa del Tercer Mundo. En caso de que optaran por sus intereses económicos inmediatos romperían la unidad del Tercer Mundo y lo privarían de la participación de varios de sus miembros más activos e influyentes en el diálogo Norte-Sur.

\section{Internacionalización de la producción}

Desde mediados de la década del 70 cobra actualidad en los países industrializados el tema de una nueva división internacional del trabajo debido a los cambios que se producen en sus economías, tales como el alto costo de la energía y la mano de obra, así como a la escasez de materias primas y a un deterioro en los términos del intercambio de las manufacturas frente 
a los productos básicos. Se considera deseable una distribución de tareas basada en la asignación de actividades intensivas en mano de obra y en recursos naturales a los países en desarrollo y las industrias de tecnología avanzada a los países industrializados.

Las empresas transnacionales estadounidenses y japonesas habían desarrollado desde mediados de la década del sesenta una vigorosa expansión hacia los países en desarrollo instalando industrias intensivas en mano de obra dedicados a la exportación e integrando los procesos productivos con diversos puntos geográficos de producción y ensamble. Este desplazamiento permitió que el esfuerzo industrial en .EE.UU. y Japón se concentrara en la investigación y desarrollo de industrias de tecnología avanzada. Europa advierte desde la década pasada la conveniencia de seguir una estrategia similar para no quedar a la zaga de sus competidores y fomenta la formación de grandes empresas que comienzan a expandirse.por el mundo industrializado y por los países en desarrollo. En todos los casos los gobiernos emprenden políticas internas de reestructuración industrial que en cierta manera complementan la estrategia de sus empresas transnacionales, introduciendo mecanismos de compensación para las pérdidas de empresas y empleos debidas a la producción externa.

La tendencia del Norte a internacionalizar la producción coincide con el cambio de estrategia de desarrollo industrial, de algunos países en desarrollo que los lleva a abandonar el modelo de sustitución de importaciones por el de exportación de manufacturas y a negociar con las transnacionales la implementación de la nueva estrategia.

Lo que se propugna y discute a partir de mediados de la década del 70 es la conveniencia de acelerar y ampliar estas tendencias, lo cual se dice traería un mejor aprovechamiento de las ventajas comparativas nacionales para el comercio mundial.

La llamada nueva división internacional del trabajo es en última instancia una interpretación de un vasto proceso que viene operando en la economía mundial en los últimos quince años. Sobre este proceso sólo existen consensos de carácter muy general, como el de la Comisión Trilateral, que afirma la naturaleza evolutiva del sistema capitalista o el de la ONUDI, que reclama un $25 \%$ de la producción manufacturera para el Tercer Mundo en el año 2000, pero a nivel de actitudes y políticas más específicas se encuentra en los países industrializados acciones poco coordinadas y aun contradictorias hacia él. Fundamentalmente no existen ideas claras respecto a la forma en que se deben producir los reajustes estructurales que este proceso conlleva, ni respecto a su extensión temporal ni a los costos que involucra para los países industrializados.

Por el lado de los países en desarrollo las ideas respecto a su transfor- 
mación están basadas principalmente en la experiencia de industrialización acelerada de los países del Sudeste Asiático. Este proceso tuvo lugar dentro de un modelo especial de desarrollo con amplia colaboración del capital extranjero y las empresas transnacionales, proliferación de enclaves territoriales, modalidades de subcontratación y empleo de técnicas muy modernas.

La configuración actual del proceso por parte de los países en desarrollo es de una concentración de la exportación de manufacturas desde diez países, incluidos los del Sudeste Asiático que en 1978 representaron el $61 \%$ del total. De América Latina sólo Brasil y México se hallan en este grupo. (Colombia está detrás de ellos).

Por consiguiente la internacionalización de la producción como perspectiva reposa sobre el supuesto de la adopción por los países en desarrollo de estrategias de desarrollo industrial implementados en estrecha vinculación con las empresas transnacionales y se basa en la experiencia de un pequeño porcentaje de estos países. Esta experiencia revela una industrialización dependiente del exterior y de las fluctuaciones de las economías industrializadas que brinda a los países una participación parcial en el proceso de la producción - por la integración transnacional de la misma - y que se frena mayormente al nivel de las industrias ligeras.

Sin embargo, es posible para los países en desarrollo participar en la internacionalización de la producción buscando formas diferentes de asociación con las empresas transnacionales y con el exterior, promoviendo el desarrollo industrial de menor dependencia.

La asociación con empresas transnacionales para el desarrollo industrial y la exportación de manufacturas resulta compatible aun con la estrategia de las necesidades básicas si se considera aquella actividad solamente como uno de los ingredientes del proceso de desarrollo. Mientras que el nivel tecnológico adecuado para la economía en su conjunto puede ser intermedio, las industrias de exportación requieren tecnologías avanzadas que las empresas transnacionales están en condiciones de proveer. En consecuencia, para conseguir una participación positiva de las transnacionales en la industria, acorde con los lineamientos generales del desarrollo nacional, la clave radicará básicamente en la capacidad que logren montar los países en desarrollo - individualmente o preferiblemente dentro de esquemas cooperativos - para evaluar proyectos y sostener negociaciones equilibradas con las empresas transnacionales. 


\section{Pers pectiva del Sistema: EI ROl de la semiperiferia}

Existen dos niveles de análisis del sistema económico internacional: un nivel de proceso que enfoca el comportamiento a corto plazo de los actores dentro de un conjunto más o menos constante de instituciones, tendencias y expectativas y un nivel estructural, relacionado con los factores económicos y políticos de influencia a largo plazo que determinan el marco en el que se desenvuelven los actores. En este segundo nivel el interés recae primordialmente sobre la forma en que surgen y se desenvuelven las instituciones, tendencias y expectativas del primer nivel y la manera en que afectan el comportamiento de los actores.

La economía mundial funciona como un sólo sistema capitalista en el cual se puede distinguir tres tipos de actores estatales: los países industrializados, los países en desarrollo y los países socialistas, estos últimos configurando una categoría especial que participa moderadamente en el sistema y cuenta con una modalidad diferente para la distribución interna de los beneficios. Análisis neomarxistas recientes, como el de Wallerstein, introducen una categoría adicional, la semiperiferia que resulta esencial para explicar el funcionamiento del sistema. Se trata de países de desarrollo intermedio entre los países industrializados (centro) y los países en desarrollo (periferia) que ostentan básicamente tasas intermedias de costo de la mano de obra y de beneficio del capital y que cumplen dos roles centrales en el sistema capitalista:

a) Políticamente, evitan la polarización de las fuerzas del sistema y de esta manera previenen el desencadenamiento de conflictos desintegradores entre los sectores de altos y bajos ingresos de la economía mundial. La semiperiferia, como todo grupo intermedio, tiende a verse primordialmente por encima del sector de más bajos ingresos y no por debajo del sector privilegiado, por lo cual tiene función de nexo entre los dos sectores y apaciguadora de las tensiones del sector inferior.

b) En lo económico, ofrece oportunidades para el desplazamiento del capital de los países industrializados que poseen una costosa mano de obra y declinantes ventajas comparativas para la producción.

La semiperiferia ha sido paralelamente conceptualizada de diversas formas, entre otras, como centros "subimperialistas" (Galtung), con connotaciones político-económicas, o más recientemente como "nuevos paíindustrializados" (NICS), desde un punto de vista estrictamente económico y comercial (OCDE). En realidad es un fenómeno que surge después del período de la guerra fría como consecuencia del privilegiado tratamiento político y/o económico que las potencias del mundo industrializado dan a ciertos países del Tercer Mundo debido a su importancia política o estratégica o a sus potencialidades económicas. En la década 
pasada acceden a la semiperiferia, como conjunto, los países de la OPEP con su nueva riqueza.

La semiperiferia constituye un conjunto de países y economías dispares que básicamente tienen en común roles y beneficios similares dentro del sistema capitalista en virtud de su nivel intermedio de desarrollo. En 1975, por ejemplo, según Naciones Unidas, $40 \%$ de la inversión extranjera en el Tercer Mundo (110 países) se repartió solamente entre diez países y otro $20 \%$ entre los 13 países de la OPEP. Entre todos ellos Brasil tuvo el $13 \%$, México $7 \%$, Venezuela $6 \%$, Indonesia $5 \%$, Nigeria $4 \%$, India y Malasia 3.5\% cada uno, Argentina 3\% (disminuyendo de 5\% en 1971), Perú $2.5 \%$ (básicamente en minería) y Hong Kong, Filipinas y Trinidad $2 \%$ cada uno. La OCDE, por su parte, considera entre los diez "nuevos países industrializados" a España, Portugal, Grecia y Yugoeslavia, además de Corea y Taiwan, los cuales no aparecen en el cuadro de Naciones Unidas. Para completar esta enumeración habría que destacar entre los países de la OPEP, los roles de Arabia Saudita y Argelia en la semiperiferia y agregar a Israel dentro de la categoría, por su nivel de ingresos y crecimiento.

En suma se trata de menos de treinta países, casi todos con un crecimiento más rápido que los países industrializados y el Tercer Mundo en la década pasada, el cual se sustenta en la exportación de manufacturas o en la explotación de sus recursos naturales, señaladamente petróleo.

A nivel de los países industrializados, hemos visto que existe una pugna por adaptarse de la manera más ventajosa para cada uno a los cambios producidos en la economía internacional, en la década del 70 . Este conflicto, conjugado con la dinámica misma de crecimiento del sistema capitalista, ha llevado a una contracción global en medio de la cual se han acentuado considerablemente las presiones para la reasignación de roles y beneficios entre los actores estatales del sistema, a nivel de cada categoría y sobre todo entre categorías, donde se dan las diferencias más marcadas.

La reasignación de roles y beneficios puede tener lugar de dos maneras: mediante cambio de los actores que desempeñan los diferentes roles o a través de una redistribución de los beneficios correspondientes a los roles, con una tendencia equilibradora. A través de la historia del sistema capitalista muchas veces se ha planteado formalmente la necesidad de cambios mediante una redistribución de los beneficios pero los verdaderos cambios han sido al final de sustitución de actores para los roles privilegiados, hecho comprensible desde que una clara desigualdad en los beneficios necesita subsistir como principal motivación para el funcionamiento del sistema.

Concretamente en la actual coyuntura los cambios de roles y beneficios 
en el sistema económico internacional se plantean en tres instancias: entre los países industrializados algunos actores como Alemania Federal y. Japón pugnan por mejorar sus roles mientras otros como Inglaterra, tratan de evitar la declinación que los podría excluir de la categoría privilegiada; en la semiperiferia se dan fuertes presiones para participar en mayor grado de los beneficios del centro, en tanto que actores como Brasil y México tratan de acceder individualmente al centro; entre la periferia y la semiperiferia países como los del Grupo Andino intentan asentarse, a través de una estrategia comunitaria, en la segunda categoría, en la cual cada uno de ellos, por distintas razones, tiene un pie.

Para definir la conformación del centro durante esta década serán decisivos los patrones de producción industrial que alcancen ciertos países industrializados y de la semiperiferia que aparecen aproximarse a un inminente cambio de roles. Baste señalar, a manera de ilustración, que entre 1970 y 1977 los diez países considerados como "nuevos industrializados" por la OCDE aumentaron de $6.61 \%$ a $9.28 \%$ su participación en la producción industrial mundial mientras que la de Inglaterra disminuyó de $5.26 \%$ a $4.16 \%$ y en menor escala declinó también la participación de los demás países europeos. Por otro lado la OCDE señala que la industrialización tendrá avances espectaculares hasta el año 2000 en algunos países del Tercer Mundo y que las perspectivas de crecimiento de los "nuevos industrializados" serán excelentes si el mundo industrializado les abre sus mercados y atiende en parte sus requerimientos financieros. En cambio, ya hemos visto que la misma organización pronostica una declinación de la participación de Europa en el ingreso mundial. Al respecto algunos autores ven en las convenciones de Lomé un renovado esfuerzo de las Gomunidades Europeas por preservar la dominación sobre sus ex colonias y defender con ello su posición central en el sistema capitalista que se halla amenazada.

Los países de la semiperiferia ya han conseguido participación en primer nivel de ejercicio del poder económico en el sistema, interviniendo activamente en los flujos de inversión (OPEP) y de comercio ("nuevos países industrializados"). Para conseguir acceso al segundo nivel de poder económico, el de elaboración de reglas del juego, han impulsado a la causa del Tercer Mundo en pos de un Nuevo Orden Económico Internacional, el cual plantea nuevas reglas para la redistribución de los beneficios del sistema.

Las reglas e instituciones del actual sistema económico fueron creadas básicamente para servir los intereses y preferencias de los países industrializados. Bajo una apariencia liberal el sistema obedece en realidad en muy poca escala a las leyes de la oferta y la demanda, pues las condíciones de las transacciones son mayormente fijadas por los pro- 
ductores o por autoridades especiales, en ambos casos pertenecientes a los países industrializados.

Teniendo en cuenta la experiencia histórica de los intentos de reforma de la economía capitalista podemos pensar que los mecanismos del NOEI, en la forma que se implementen, no servirán fundamentalmente para modificar las características oligopólicas de los mercados internacionales y a equilibrar con ello los beneficios de los actores, sino para facilitar la participación en los oligopolios de nuevos actores de la semiperiferia que así aumentarán los beneficios de su participación en el sistema.

Díaz-Alejandro habla de los "nuevos oligopolistas" que intentan ganar posiciones en los mercados mundiales, dominados por los oligopolistas tradicionales del Norte. Estos actores buscan incrementar su poder económico para mejorar las condiciones de intercambıo de sus materias primas y productos básicos así como de sus nuevas exportaciones de manufacturas y de sus importaciones de maquinaria y tecnología. La cartelización de los mercados de productos básicos, por ejemplo, que es un componente esencial del NOEI, representa. una transferencia de poder monopólico de los países industrializados a algunos países en desarrollo, especialmente de la semiperiferia. Los países de la semiperiferia han comenzado a desarrollar también empresas transnacionales las cuales exhibieron, una expansión a niveles predominantemente regionales durante la década pasada, según da cuenta el último informe de Naciones Unidas sobre las Transnacionales (1978).

Los países industrializados en tanto fomentan la existencia de la semiperiferia para atenuar las tensiones con el Tercer Mundo, se oponen al aumento de sus beneficios con relación al centro así como al eventual incremento o sustitución de actores del centro. Comprenden que la intención de las demandas reformistas de la semiperiferia no es trastornar el funcionamiento de los mercados internacionales, dado el creciente poder exportador y las necesidades de capital y tecnología de los países que la componen, sino simplemente conseguir una mayor participación en el manejo del intercambio. Pero temen que las concesiones resultantes pueden contribuir al deterioro de la hegemonía tecnológica industrial del centro y por esta razón invocan contra ellas la supuesta inalterabilidad de los principios liberales de la economía internacional.

La semiperiferia por su parte se confunde con el Tercer Mundo y asegura su respaldo político demandando una redistribución global de beneficios que mejore la participación de los países más pobres en la economía mundial. Sin embargo los mecanismos más concretos e inmediatos del NoEI, como el Sistema General de Preferencias, el Programa Integrado de Productos Básicos o el alivio de la deuda, están concebidos para bene- 
ficiar sobre todo a los países en desarrollo de mayores recursos, vale decir a los que están en capacidad de exportar bienes y servicios.

En este sentido es importante advertir que el Programa Integrado no está dirigido a modificar los términos del intercambio en favor de los productos básicos ni a asegurar a los productores un mayor aprovechamiento de esta aparente tendencia. Ello se debe a que la exportación de manufacturas es uno de los principales intereses de la semiperiferia, cuyos beneficios superan claramente a los de la exportación de productos básicos.

Otras demandas del NOEI no muestran efectos fácilmente mensurables para el Tércer Mundo y se relacionan más propiamente con la configuración hipotética y gradual del Nuevo Orden que con concesiones inmediatas y específicas. En esta condición están los cambios en la toma de decisiones y el funcionamiento de los principales organismos económicos internacionales y los códigos de conducta para ciertas actividades económicas.

Todos estos aspectos del NOEI han ocasionado ya y pueden conducir a una cierta mejora en las condiciones de competencia en el sistema económico, aunque sin alterar sus estructuras de poder y sin beneficiar específicamente a los países más pobres. En cambio el clima de transformación generado por el diálogo Norte-Sur y los logros del NOEI vienen sirviendo hasta ahora eficazmente para propiciar el ajuste de la economía mundial a una participación más ventajosa de los países emergentes de la semiperiferia y a facilitar el acercamiento de algunos de ellos al centro del sistema.

Por consiguiente, en esta década puede esperarse significativos cambios en la estratificación económica mundial de los países, con un relativo acortamiento de la distancia entre el centro y la semiperiferia y un mayor distanciamiento de la semiperiferia del resto del Tercer Mundo (que podría hacer peligrar la unidad de esta fuerza política). En buena cuenta lo que ocurriría será la cristalización de una clase media de naciones emergentes que llegará finalmente a un entendimiento con el centro y que tendrá una expansión de sus atribuciones y beneficios en el sistema económico.

La formación de esta clase media quitará poder a la periferia y reducirá la movilidad vertical entre las dos categorías, de manera que aquellos países de la semiperiferia que no obtengan tasas de crecimiento acordes con.las del conjunto quedarán relegados a una periferia más estrecha, desvalida y oprimida que la del pasado inmediato.

Las condiciones individuales del crecimiento en la semiperiferia se harán más difíciles. Para mantener las tasas de la década pasada, los países tendrán que diversificar en alguna medida sus actividades de crecimiento, buscando un mayor equilibrio en él e. incrementando indi- 
vidual o colectivamente su grado de autosuficiencia. En particular el panorama se complicará para algunos países exportadores de manufacturas que han basado su crecimiento en una mano de otra abundante y barata - tipo Sudeste Asiático- y tendrán que competir no sólo con el resto de la semiperiferia y el centro sino con otros candidatos a la semiperiferia - como Tailandia y Sri Lanka - que ofrecerán a la inversión extranjera mano de obra más barata en similares condiciones. Los países de la OPEP por su parte, tendrán que preocuparse porque sus recursos financieros promuevan una acelerada industrialización y les aseguren una inserción diferente en la economía mundial después del año 2000 que les permita mantener sus niveles de ingreso.

Por otro lado esta década presenciará el inicio de las tareas de organización de la nueva clase media en las cuales los pesos específicos que consigan acumular los distintos actores a base de sus potenciales, afinidades y complementariedades serán decisivos para el surgimiento de coaliciones y líderes que consoliden su pertenencia a la categoría y les aseguren influencia en la determinación del comportamiento de la semiperiferia frente a las otras dos categorías. En este punto es conveniente advertir que varios de los actuales líderes de la semiperiferia -como Brasil y México - no visualizan su futuro dentro de esta categoría sino desarrollan estrategias mucho más ambiciosas encaminadas a acceder eventualmente al centro. De manera parecida, países como España, Portugal, Grecia y Yugoeslavia se hallan intimamente vinculados a la problemática económica europea y semi-integrados al centro. 